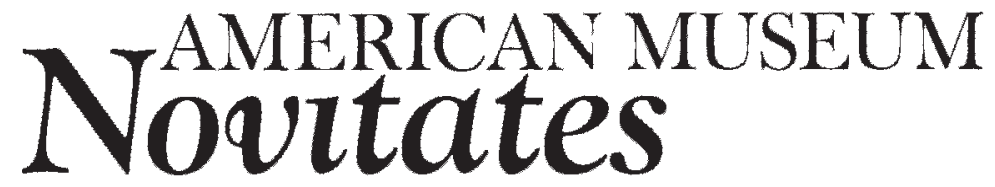

PUBLISHED BY THE AMERICAN MUSEUM OF NATURAL HISTORY CENTRAL PARK WEST AT 79TH STREET, NEW YORK, NY 10024 Number 3674, 19 pp., 16 figures, 1 table

November 30, 2009

\title{
Osteology of Andescynodon (Cynodontia: Traversodontidae) from the Middle Triassic of Argentina
}

\author{
JUN LIU' ${ }^{1}$ AND JAIME POWELL ${ }^{2}$
}

\begin{abstract}
All available specimens of Andescynodon mendozensis and Rusconiodon mignonei are examined and restudied, and the latter species is regarded as a junior synonym of the former. The postcranial skeleton of this species is described for the first time; it generally shows primitive features of traversodontids. Andescynodon mendozensis is a small- to medium-sized traversodontid characterized by 9 11 upper postcanines in adults (fewer in larger individuals), the transverse ridge of upper postcanines lying anteriorly on the tooth, paracanine fossa penetrating the skull roof in adult; it is differentiated from Pascualgnathus by relatively flatten skull, shorter and narrower temporal region, presence of four rather than three upper incisors.
\end{abstract}

\section{INTRODUCTION}

Traversodontids are a common member of the terrestrial Triassic fauna, especially in South America. The family name comes from the buccolingually expanded postcanine teeth, which are linked to an herbivorous or omnivorous diet. Andescynodon mendozensis and Rusconiodon mignonei are early representatives of the Traversodontidae, and both taxa are traditionally viewed as occurring in the Rio Mendoza Formation and being among the most basal traversodontids (Godefroit and Battail, 1997; Abdala and Ribeiro, 2003; but see Abdala et al., 2006). However, recent work has shown that these cynodonts actually come from the Cerro de las Cabras Formation (Middle Triassic) (Zavattieri and Arcucci, 2003), co-occurring with Cromptodon mamiferoides. Andescynodon and Rusconiodon were

\footnotetext{
${ }^{1}$ Key Laboratory of Evolutionary Systematics of Vertebrates, Institute of Vertebrate Paleontology and Paleoanthropology, Chinese Academy of Sciences, Beijing, China 100044 (liujun@ivpp.ac.cn); Division of Paleontology, American Museum of Natural History.

${ }^{2}$ Paleontologia de Vertebrados Lillo, Universidad Nacional de Tucuman, Argentina.
} 
established by Bonaparte (1967, 1970), who gave a brief description of the skull and dentition of each genus. Subsequently, Quiroga (1980) studied endocasts of Andescynodon, whereas Goñi (1986) and Goñi and Goin $(1987,1988)$ studied the postcanines in detail. Goñi and Abdala (1989) briefly described the skull, lower jaw, and dentition of Rusconiodon. In this paper, we restudy all the material pertaining to these taxa, especially the postcranial skeleton.

Rusconiodon is similar to Andescynodon in its skull and tooth morphology, except for the canine hypertrophy and supposed dorsal and labial perforation of the snout by paracanine fossae in Rusconiodon (Goñi and Abdala, 1989). In all the collected material from the Cerro de las Cabras Formation, only PVL 3834, PVL 3840, PVL 3892a, b, c, d, and PVL 3900 have ever been referred to Rusconiodon (Goñi and Abdala, 1989; Abdala, 2000). Given the morphological similarity of the two species and their identical geographic and temporal distributions, we want to test the hypothesis that the species represent a single taxon.

\section{Abbreviations}

Institutional: MLP, Museo de La Plata, Argentina; PVL, Colección de Palaeontología de Vertebrados, Instituto Miguel Lillo, Universidad Nacional de Tucumán, Argentina.

ANATOMicAl: A, angular; acr, acromion process; a e, anterior edge of the medial end of the clavicle; ap, anapophysis; Bo, basioccipital; Bs, basisphenoid; C, canine; cf, clavicular flange; cp, capitulum; D, dentary; dc, deltopectoral crest; ec, ectopicondyle; en, entepicondyle; Eo, exoccipital; Ep, epipterygoid; F, frontal; f ec, ectopicondylar foramen; f en, entepicondylar foramen; fj, foramen jugulare; fo, fenestra ovalis; f spc, supracoracoid fossa; g, glenoid; gr, groove in dorsal edge of the ischium; gt, greater tuberosity; h, head; I, incisor; icl, interclavicle; if, intertrochanteric fossa; il, ilium; is, ischium; is $\mathbf{r}$, ischial ridge; $\mathbf{J}$, jugal; jf, jugular formamen; L, lacrimal; It, lesser tuberosity; $\mathbf{M}$, maxilla; $\mathbf{N}$, nasal; ob f, obturator foramen; $\mathbf{O p}$, opisthotic; $\mathbf{P}$, parietal; pcf, paracanine fossa; $\mathbf{p}$ e, posterior edge of the medial half of the clavicle; Pf, prefrontal; Pm, premaxilla; PI, palatine; Po, postorbital; poz, postzygophysis; pp, paroccipital process; ppf, pterygo-paroccipital foramen; Pro, prootic; prz, prezygophysis; Pt, pterygoid; ptf, posttemporal fenestra; pu, pubis; pu p, pubic plate; Q, quadrate; rs, rib shaft; Sa, surangular; Sm, septomaxilla; sp, neural spine; Sq, squamosal; sr, sacral rib; th, trochlear; trf, transverse flange of the pterygoid; tr $\mathbf{m j}$, trochanter major; tr $\mathbf{~ m n}$, trochanter minor; trp, transverse process; $\mathbf{t} \mathbf{t}(\mathbf{c})$, tuberosity for origin of coracoid head of triceps.

\section{SYSTEMATIC PALEONTOLOGY}

THERAPSIDA BROOM, 1905

CYNODONTIA OWEN, 1861

\section{TRAVERSODONTIDAE VON HUENE, 1936}

\section{ANDESCYNODON BONAPARTE, 1967}

SYNONYM: Rusconiodon Bonaparte, 1970.

TYPE SPECIES: Andescynodon mendozensis Bonaparte, 1967.

Diagnosis (revised): small- to mediumsized traversodontid characterized by $9 \sim 11$ upper postcanines in adults (fewer in larger individuals), transverse ridge of each upper postcanine lying anteriorly on the tooth, paracanine fossa penetrating the snout in adult; differentiated from Pascualgnathus by relatively flattened skull, shorter and narrower temporal region, presence of four rather than three upper incisors.

Andescynodon mendozensis Bonaparte, 1967

Synonym: Rusconiodon mignonei Bonaparte, 1970.

Holotype: PVL 3833, incomplete skull.

Stratum typicum: Cerro de las Cabras Formation.

Locus TYPICUS: $5 \mathrm{~km}$ to the west of Villa de Potrerillos, Province de Mendoza, Argentina.

Diagnosis: As for genus, of which this is the only known species.

Age: Middle Triassic.

REFERRED SPECIMENS: All specimens of Andescynodon and Rusconiodon in PVL as identified by Abdala (2000). The following specimens were used in this study. Skull and 

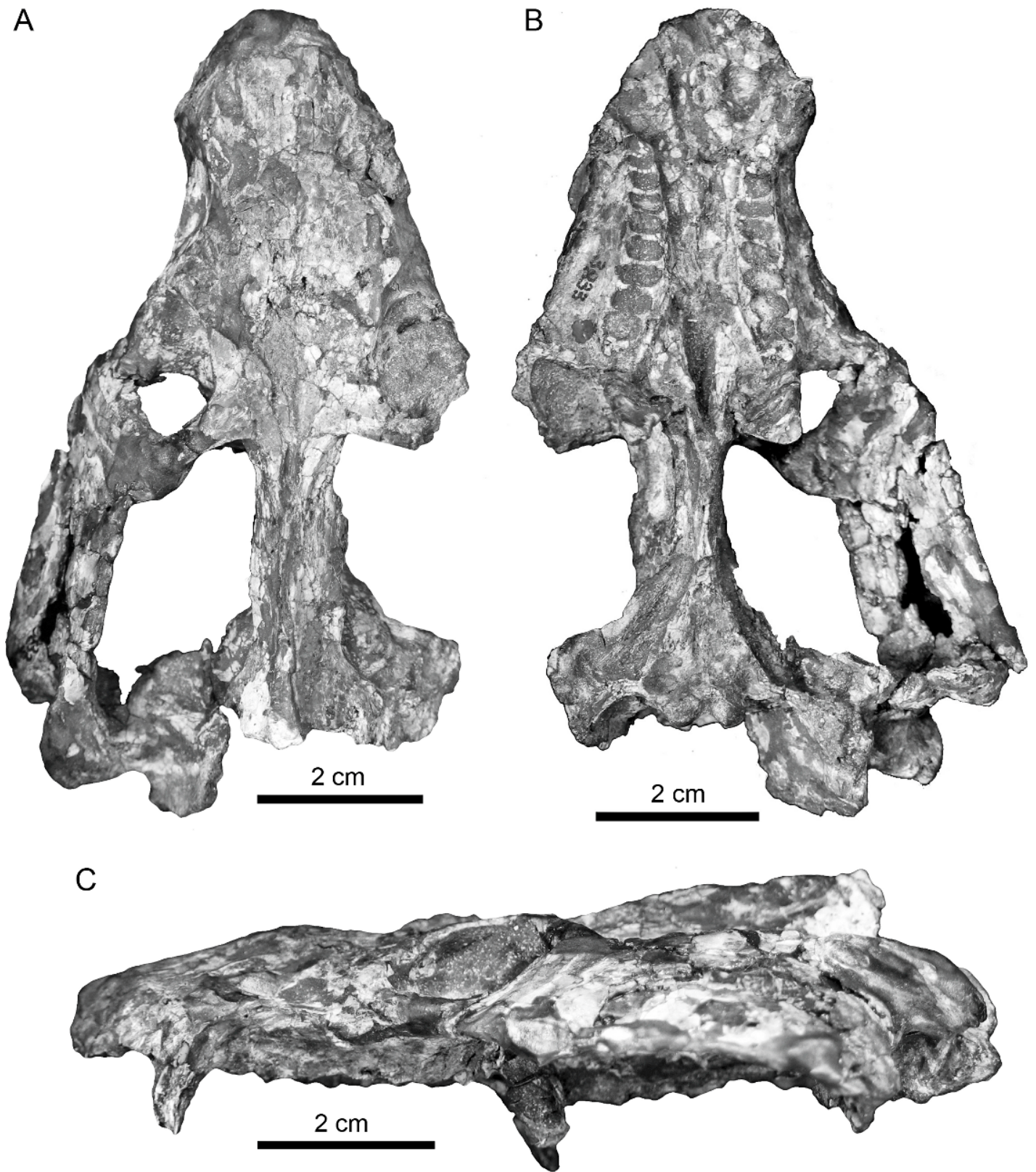

Fig. 1. The holotype of Andescynodon mendozensis (PVL 3833) in A, dorsal; B, ventral; and C, lateral views.

mandible: PVL 3833 (holotype of Andescynodon mendozensis, fig. 1), 3834, 3840 (holotype of Rusconiodon mignonei, fig. 2), 3890, 3892 (a, b, c, d), 3894, 3894-1, 3899, 3900, 4390. Postcranial skeleton: PVL 3890, part of scapula, pelvis, two humeri, left ulna, femur; PVL
3894, one isolated vertebra, vertebral column with associated ribs, clavicles, portion of left pelvic girdle, humerus, femur; PVL 4390 (juvenile), three articulated vertebrae and one isolated vertebra, ribs, part of pelvis, right ilium; PVL 4423, scapula; PVL 4424-4427, 

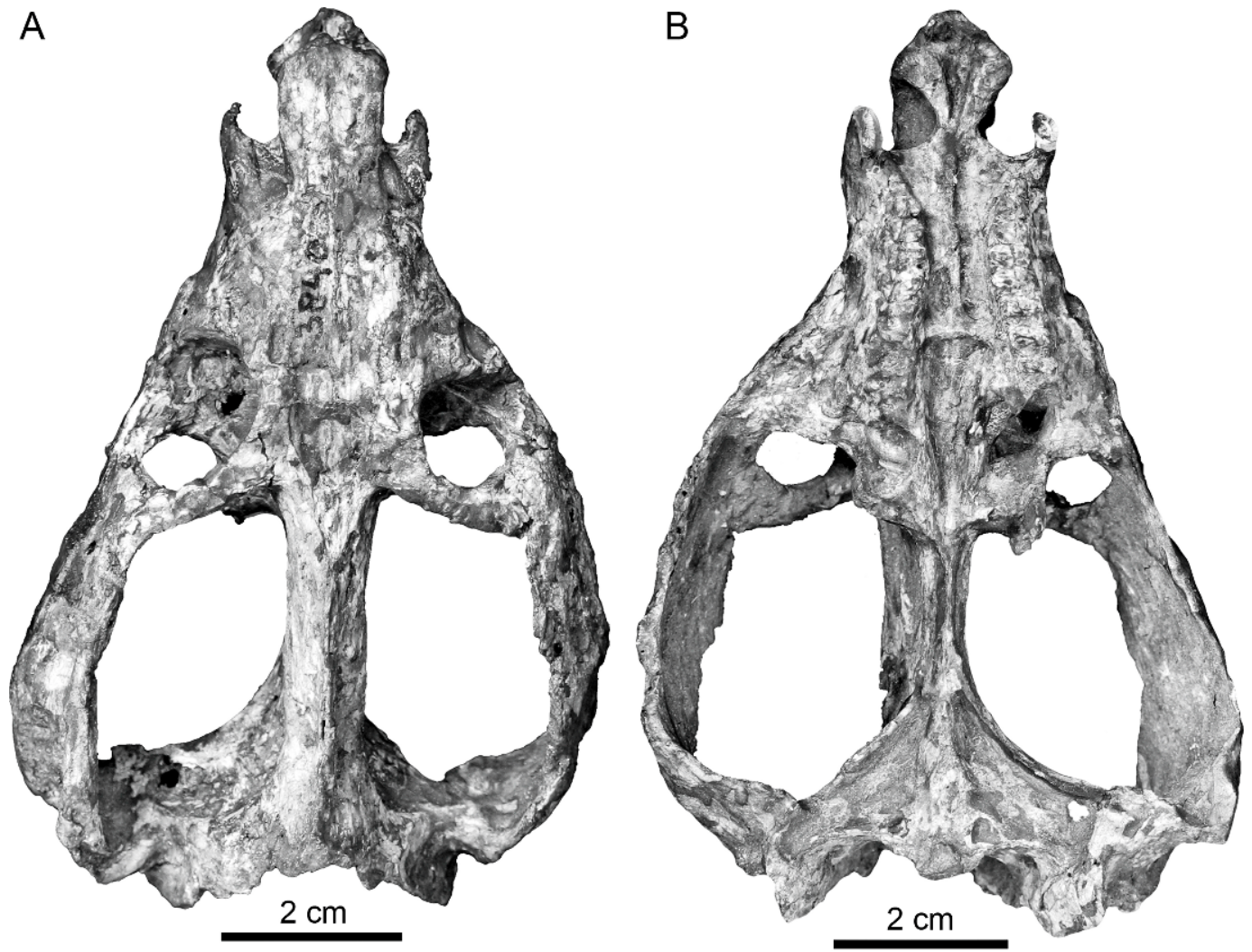

C

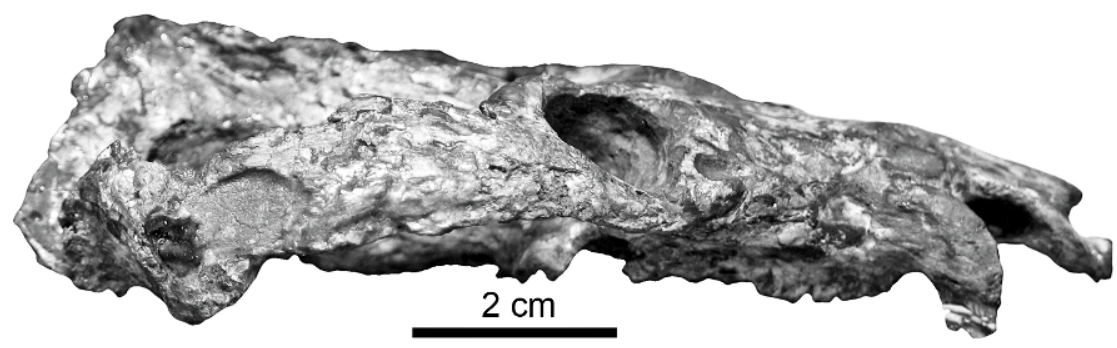

D

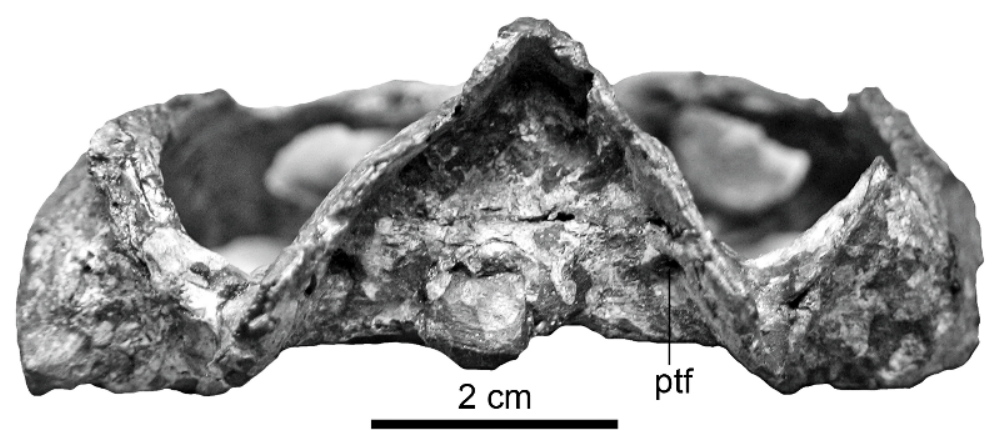

Fig. 2. The holotype of Rusconiodon mignonei (PVL 3840) in A, dorsal; B, ventral; C, lateral; and D, occipital views. 

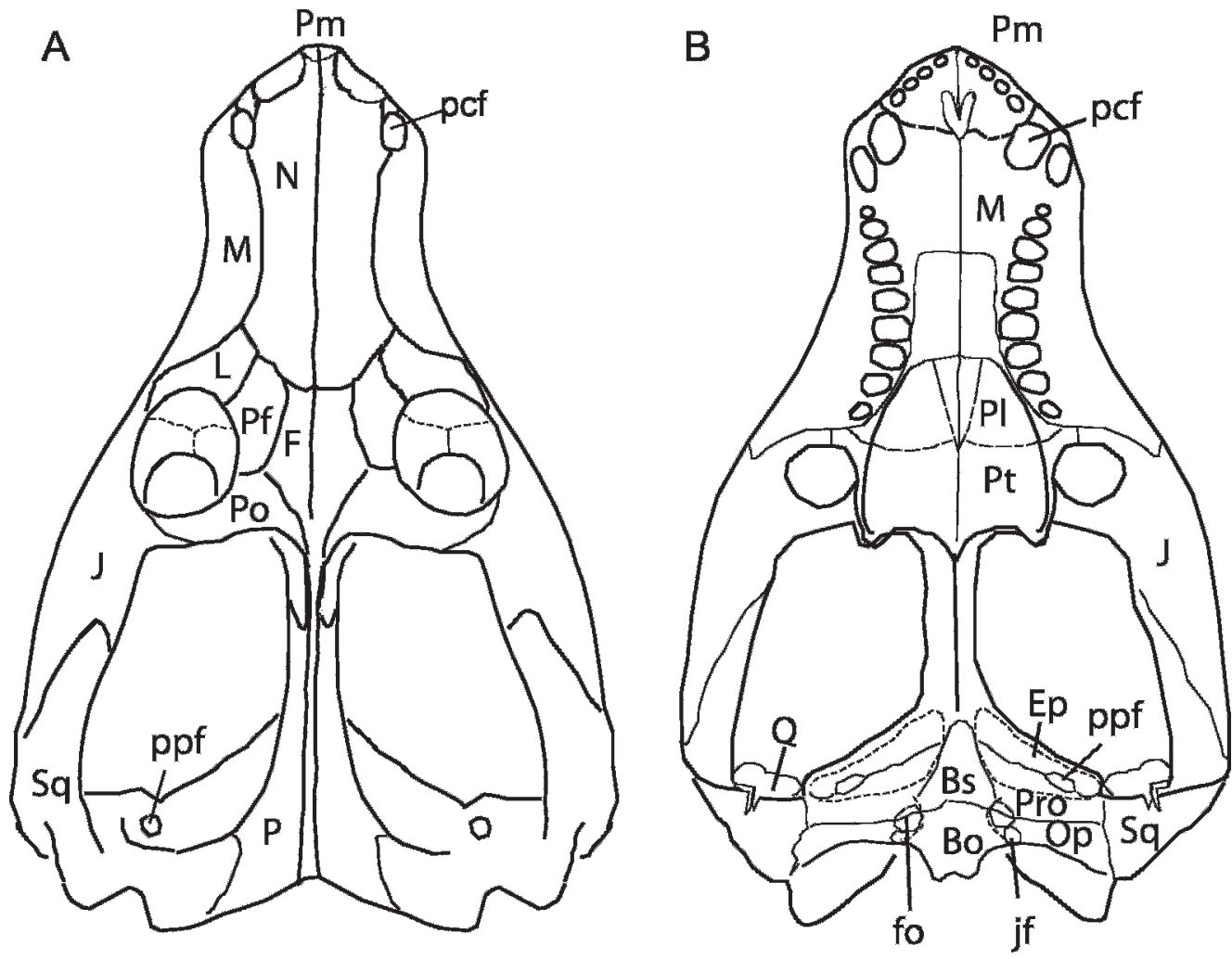

C

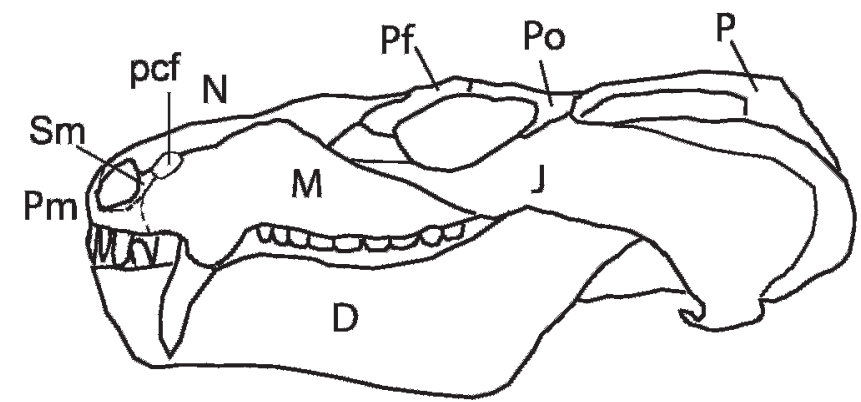

Fig. 3. Reconstruction of the skull and lower jaw in $\mathbf{A}$, dorsal view; $\mathbf{B}$, ventral view; and $\mathbf{C}$, lateral view. Abbreviations as in text.

four humeri; PVL 4428, right pectoral girdle; PVL 4432, one incomplete vertebra; PVL 6226, incomplete pelvis.

\section{MORPHOLOGICAL DESCRIPTION}

\section{SKULL}

The sutures are not well preserved in any specimen, and the drawings (fig. 3) are composites of different specimens. The skull is small to medium sized. The basicranial length reaches $137 \mathrm{~mm}$ in PVL 3900, but in most specimens is less than $100 \mathrm{~mm}$ (table 1).

The snout is only slightly expanded, and its length is subequal to that of the temporal region. The zygomatic arch flares posteriorly and the skull's maximum width occurs near the posterior end. The external nares are separated by an internarial bar. The premaxilla is overlapped by the nasal and terminates between the external nares. This part of the 


\section{TABLE 1}

Measurements of PVL specimens (in mm except for UTN)

(SL, skull length from the tip of the snout to the occipital condyle; TEL, total length of temporal region; SW, skull maximum width, occurring in temporal region; $\mathrm{OH}$, occipital height; $\mathrm{UCH}$, upper canine height, defined as the prominence of the canine beyond the alveolar margin; LCH, lower canine height; UTN, upper postcanine teeth number.)

\begin{tabular}{lrcccccc}
\hline \hline Specimen & SL & TEL & SW & OH & UCH & LCH & UTN \\
\hline 3833 & 86 & 35 & 72 & 22 & - & - & 10 \\
3834 & 76 & 30 & 60 & 20 & 9.6 & - & 10 \\
3836 & 65 & 28 & 53 & 18 & - & - & 8 \\
3840 & 91 & 41 & 62 & 22 & - & - & 9 \\
3890 & 86 & 40 & - & - & 11 & - & - \\
$3892 \mathrm{a}$ & 103 & 42 & - & 36 & 18 & 19 & 10 \\
3894 & 79 & 27 & - & & 7.7 & & 11 \\
$3894-1$ & 87 & 32 & 57 & 21 & - & - & - \\
3899 & 69 & 26 & 57 & 24 & 6 & $>16$ & - \\
3900 & 137 & 44 & 82 & 33 & 19 & & 7 \\
4390 & 55 & & & & 4 & &
\end{tabular}

snout is broken in most specimens, but the internarial bar is complete in PVL 3899 (fig. 4A). The septomaxilla lies on the posteroventral side of the external naris.

The incisive foramen is mostly enclosed by the premaxilla, although the posterior border is formed by the maxilla. A deep paracanine fossa lies anteromedial to the large upper canine. In some specimens, it is a rather large opening. The fossa is surrounded by the premaxilla and the maxilla in the palate. In PVL 3840 (the holotype of Rusconiodon mignonei), the premaxilla is separated from

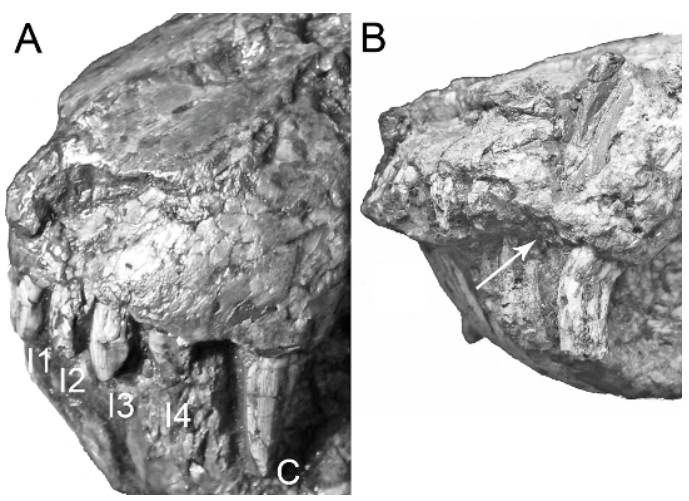

Fig. 4. A, anterolateral view of the skull of PVL 3899, showing the nasal region and incisors; B, lateral view of the skull and mandible of PVL 3900, showing the completeness of the lateral margin of the paracanine fossa. Abbreviations as in text. the maxilla in lateral view by a laterally open paracanine fossa (fig. 2C); this state was suggested to be a distinct character of Rusconiodon by Bonaparte (1970), Goñi and Abdala (1989), and Abdala (2000). Among the specimens placed in this genus by Abdala (2000), only the holotype and PVL 3892c possess this condition, which may in fact be the result of breakage. In better-preserved specimens assigned to Rusconiodon, such as PVL 3900 (fig. 4B), the premaxilla extends posteriorly as a thin plate to contact the maxilla just anterior to the upper canine. The thin plate forms the labial wall of the paracanine fossa and conceals the lower canine in lateral view. Accordingly, the labial fossa is bounded by a lateral wall in PVL 3900, despite Bonaparte's (1970) assertion that a laterally open fossa is characteristic of Rusconiodon. The upper perforation of the paracanine fossae is present in all the specimens classified as Rusconiodon by Abdala (2000), but in other specimens either the upper perforation is absent or the condition is unknown. When the perforation is present, it lies between the septomaxilla and nasal and the maxilla.

As is usual in traversodontids, the maxilla curves inward and downward from the lateral surface of the snout, forming a platform lateral to the postcanine teeth. A depression is present on the dorsalmost portion of the maxilla, close to the suture with the nasal, and 
just anterior to the orbit. The depression is rounded and well preserved in PVL 3894-1, similar to the condition in Pascualgnathus. Abdala et al. (2006) state that an equivalent fossa is also present in Langbergia, Cynognathus, Diademodon, and some traversodontids. Based on our observations, this feature can be found in all well-preserved specimens of gomphodont cynodonts although it is shallow in some, e.g., Massetognathus, and deep in others, e.g., Pascualgnathus.

The skull is slightly depressed in the middle of the interorbital region, where the posterior portion of the frontals is located. The frontals extend backward into the temporal region. Behind them, a long parietal crest is formed mostly by the parietals, although the postorbitals contribute to the anterior part of the crest. The squamosals and parietals extend well backward, concealing the occipital plate in dorsal view.

The posterior margin of the skull roof is formed by the conjoined parietals and squamosals. No parietal foramen is present. The squamosals extend laterally and slightly posteriorly away from the parietal crest, and the right and left halves of the posterior margin of the skull generally come together in an obtuse angle in dorsal view. The acute angle in PVL 3892 and 3900 is possibly unnatural, formed by the lateral compression of the specimens.

A small jugal process is developed slightly anterior to the level of the posterior border of the orbit in PVL 3894-1. Perhaps because of poor preservation, this feature cannot be observed in other specimens. As in Massetognathus pascuali, the lower margin of the zygomatic arch curves slightly dorsally, the anterior part is nearly straight, and slightly higher than the ventral margin of the maxilla. This differs from the strongly dorsally curved zygomatic arch in Pascualgnathus. The zygomatic arch is deep dorsoventrally, hiding most of the parietal region in lateral view. The jugal extends nearly to the posterior end of the zygomatic arch, and the squamosal is exposed in a narrow area on the posterodorsal and posterior part of the arch.

The secondary palate occupies $39 \%-46 \%$ of the basal skull length; the proportion usually is lower in larger specimens. The secondary palate generally extends to the level of the

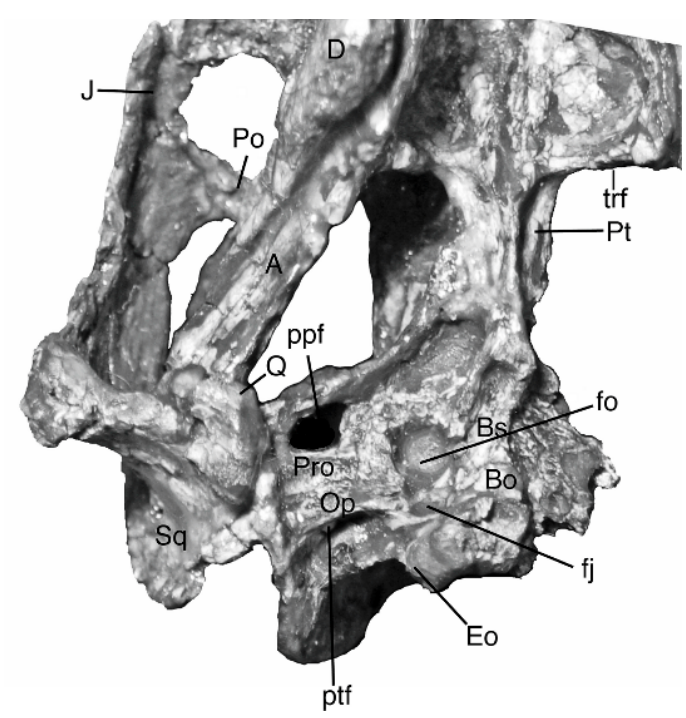

Fig. 5. Specimen PVL 3899 in ventral view. Abbreviations as in text.

third and fourth postcanines from the rear; however, it can extend to the level of the second (the left side of PVL 3840) or fifth (the left side of PVL 3894-1) tooth from the rear. The palatines contribute more than one-third of the length of the osseous secondary palate.

Posterior to the secondary palate, the central area of the palate is bounded by a pair of pronounced ridges that run posteromedially, defining a shallow midpalatal vault. The posterior part of the paired vomers forms the roof of the vault, but more anteriorly the vertical ridge of the vomers is concealed by the secondary palate.

The lateral crests extend from palatine to pterygoid, ending in the anterior portion of the thin basicranial girder as distinct medial tubercles. On either side, the lateral margins of the pterygoids extend backward as ridges that terminate in sharply pointed flanges directed strongly ventrally and slightly backward and laterally (fig. 5). The thin basicranial girder is formed by the conjoined pterygoids and parasphenoid, and the basicranium is of the type commonly seen in cynodonts. The basioccipital and basisphenoid-parasphenoid form a triangular excavated area bounded by a pair of posterolaterally directed ridges, with a thin, low crest running along the midline of the excavation. On either side, there is a large cavum epiptericum, which is bounded medi- 


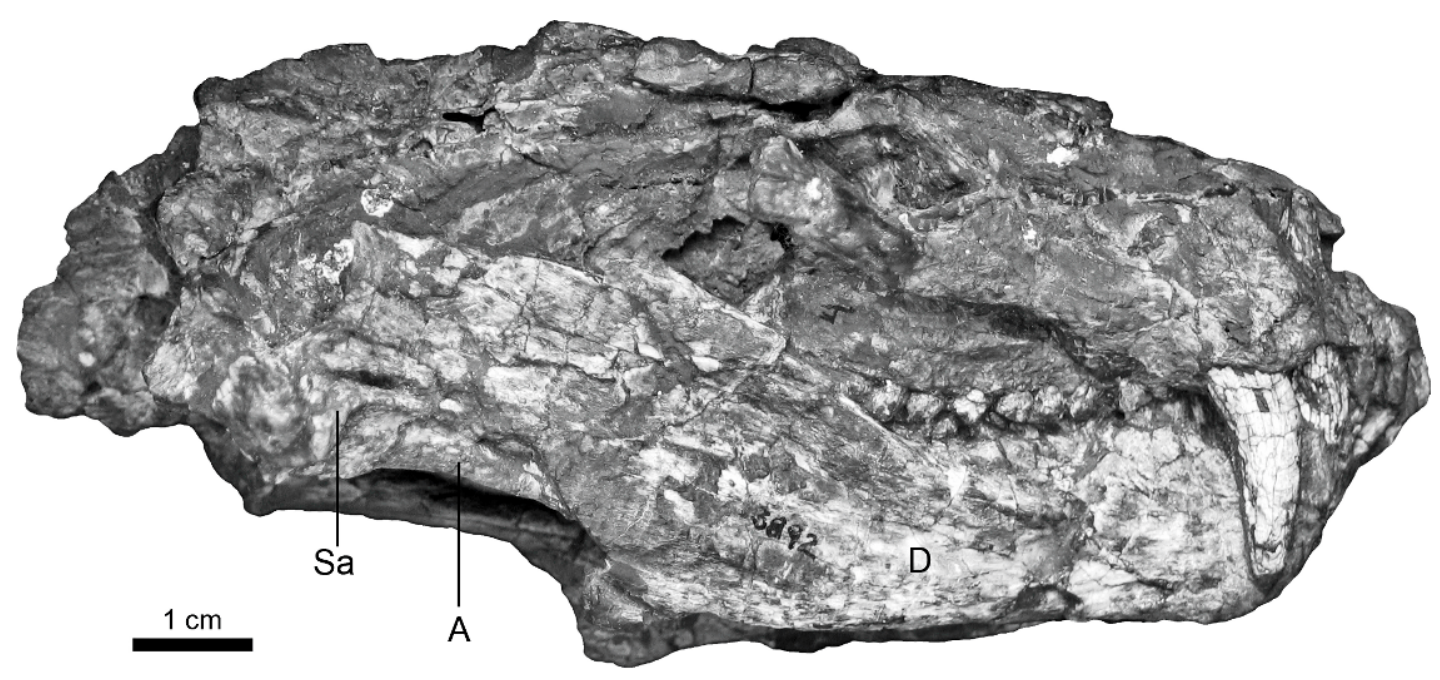

Fig. 6. Specimen PVL 3892a in lateral view. Abbreviations as in text.

ally by the basisphenoid and laterally by the epipterygoid. Posterolaterally, a pterygoparoccipital foramen is bounded posteriorly by the lateral flange of the prootic. The squamosal contacts the quadrate ramus of the epipterygoid anteriorly and the lateral flange of the prootic medially. Medial to the pterygoparoccipital foramen, the fenestra ovalis and jugular foramen lie close to the posterior end of the ridge of the basisphenoid. Distal to the epipterygoid bar, a right quadrate with a troughlike trochlear groove is still preserved in situ in PVL 3899, and this element articulates with the articular bone of the mandible.

In occipital view (fig. 2D), the skull shows a well-developed $\mathrm{V}$-shaped notch between the lambdoidal crest and the zygomatic arch. A round posttemporal fenestra lies in the concave area above the paroccipital process. Other features are obscured due to poor preservation.

\section{MANDible}

Many mandibles have been found, although in most cases the postdentary bones are not preserved. However, a few complete mandibles have been found associated with skulls (figs. 5, 6). The dentaries are fused at the symphysis. The lower edge is nearly straight, although the anterior part turns slightly downward to form a chinlike structure. In
Pascualgnathus, this border is convex. The lower edge turns smoothly upward towards the posterior end of the dentary, and the angular process does not develop as in Diademodon. The coronoid process is directed posterodorsally, at a large angle with the main body. The posterodorsal terminus of the coronoid process is slightly convex.

The splenial can be observed in ventral view in PVL 3899 and 3900. It is a thin lamina, extending anteriorly to the symphyseal region and posteriorly to the angle of the dentary. The angular is widely exposed posterior and ventral to the dentary, and forms a concave lateral surface. The surangular lies posterodorsal to the angular and is exposed below the posterior process of the dentary.

\section{DenTITION}

The incisors are poorly preserved in most specimens. Their number can be determined in a few good specimens like PVL 3899 (fig. 4), in which there are four upper and three lower incisors of moderate size, with a somewhat chisellike shape. Both the upper and the lower incisors are slightly procumbent (PVL 3892, 3894-1), contrary to the observations of Goñi and Goin (1988); the upper incisors pass lateral to the lower incisors in occlusion.

The canines vary in height among individuals of different sizes, being hypertrophied in 
some specimens. The maximum height above the alveolar ridge reaches approximately $2 \mathrm{~cm}$, for the canines of PVL 3892a and 3900. When the mandibles are occluded with the skull, the upper canines can extend down to or beyond the ventral edges of the mandibles, whereas the lower canines can penetrate the skull and are exposed in dorsal and lateral views. This is probably a natural state rather than artifact of preservation because this feature is well preserved in some specimens. This kind of canine is also developed in Pascualgnathus. The size of a vertebrate tooth usually cannot increase after eruption, so increases in tooth size can generally occur only by replacement. However, the large canines of Andescynodon and some other cynodonts seem to represent an exception. The canine total height far exceeds the depth of the jaw, so the canine must continue to grow following eruption as in modern pigs and presumably in dicynodonts. Serrations are observed on the posterior margins of the upper canines of PVL 3899.

The postcanine teeth vary in number and shape in different individuals. The number ranges from 8 to 11 upper postcanines (10 for most countable specimens) and 7 to 10 lower postcanines, with maximum values tending to occur in middle-sized specimens like PVL 3894-1. The second largest specimen, PVL3892a, has 9 postcanines, while the number is unavailable in the largest specimen, PVL 3900. Although all postcanines are gomphodont in shape in adults, subgomphodont teeth are present in the anteriormost part of the jaw in juveniles like PVL 4390, whereas the last three postcanines in these specimens are sectorial (Goñi and Goin, 1988).

In crown view, each gomphodont upper postcanine is subquadrate, around 1.5 times as broad labiolingually as long mesiodistally (fig. 7). Two major cusps develop on the anterior half to form a V-shaped area in mesial view. The labial cusp is the higher of the two, but the lingual cusp is nearly twice as wide as the labial cusp. The anterior cusps are slightly recurved posteriorly, and the lingual member of the pair occupies approximately half of the lingual side of the tooth. Posterior to the cusp, the lingual margin turns posterolabially. The posterior margin is protruded slightly anteriorly. One or more small cusps are developed posterior to and slightly separated from the anterolabial cusp on the lateral ridge, which is a nearly straight ridge that slopes upward posteriorly. These cusps are poorly preserved, and it seems that only one cusp is present in most postcanines. A basin occupies the posterior half of each tooth, lying posterior to the anterior transverse ridge and lingual to the labial ridge.

Wear occurs more prominently on the anterolingual cusp, the anterior half of which is usually entirely absent. The transverse ridge therefore seems to be displaced toward the center of the tooth, rather than lying at the anterior margin. With further wear, the transverse ridge becomes worn away (PVL 3840 ), so that the crown surface is continuous anteroposteriorly for successive teeth but concave as seen in posterior view. This resembles the last stages of wear in other traversodontids, such as Pascualgnathus and Massetognathus (personal obs.).

Each lower postcanine is subquadrate in crown view, with length and width subequal (fig. 8). The anterior part forms a high transverse ridge, partly subdivided into two cusps. The labial cusp is the higher, but the lingual cusp is wider and more steeply inclined posteriorly. In a freshly erupted tooth, small cuspules lie anterior to the anterolabial cusp; posteriorly, two minor cusps follow the main labial cusp, and combine with the main cusp to form a lateral ridge. The middle cusp is usually worn away, leaving only two well-separated cusps on the lateral portion of the tooth. A basin lies in the middle of the tooth, bounded by the ridges. As in other traversodontids, the internal side of the basin is lower than the external side, and following wear the internal side forms a deep U-shaped opening.

\section{POSTCRANIAL SKELETON}

Because two genera and species were thought to have coexisted in the Cerro de las Cabras Formation, it was previously difficult to identify some postcranial materials recovered from the formation to the level of species. However, as the two genera and species are here regarded to be synonymous (see discussion later), all postcranial skeletons are described together. 

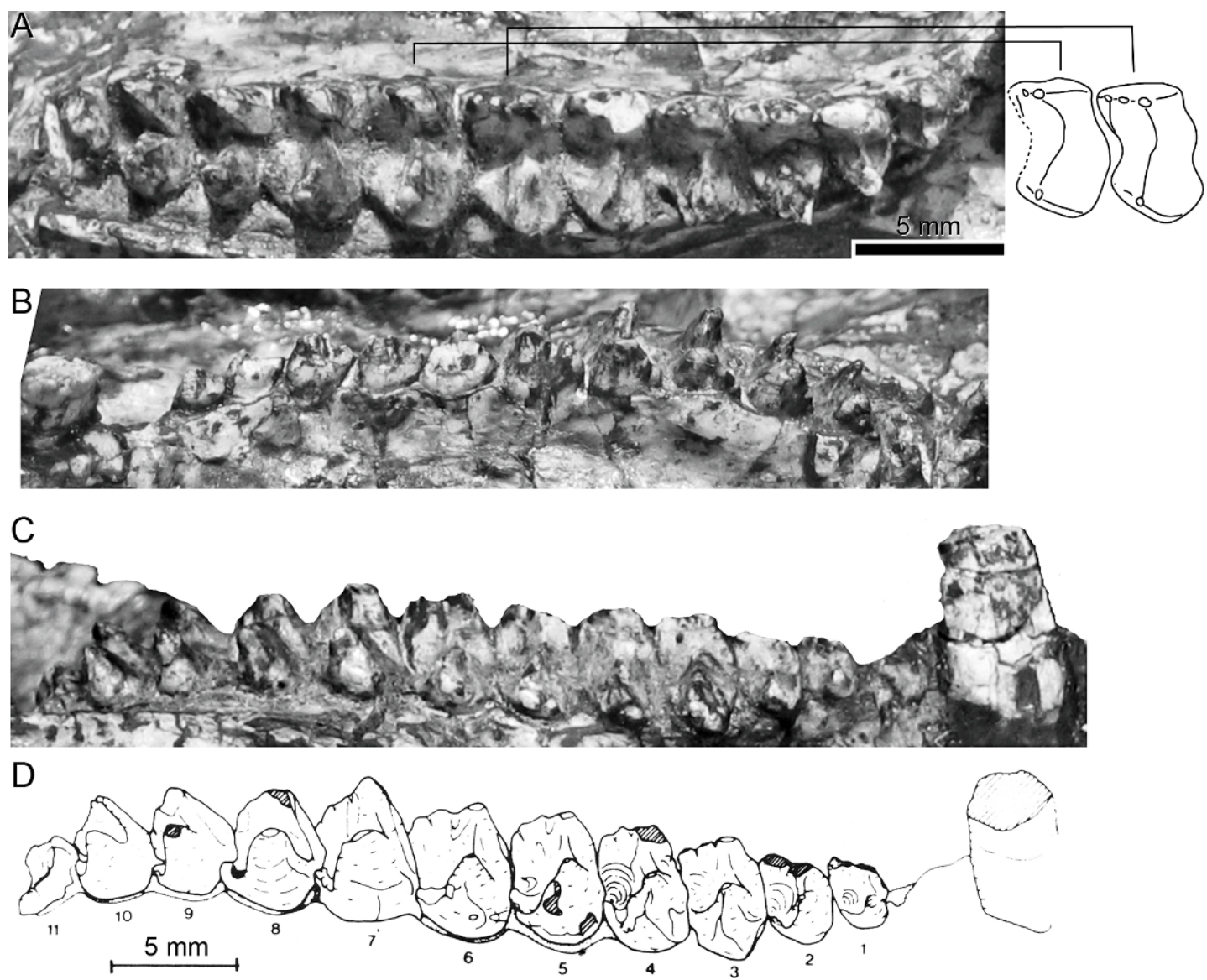

Fig. 7. Upper canine and postcanines on right side (PVL 3894-1) in A, crown view; B, labial view; C and D, lingual view. D from figure 1 of Goñi and Goin (1988). Anterior is at right except in B, in which anterior is at left.

\section{VERTEBRAE AND RIBS}

Dorsal REgION: One isolated vertebra of PVL 3894 looks similar to an anterior dorsal of Massetognathus (Jenkins, 1970: fig. 1C) and is therefore identified as an anterior dorsal (fig. 9A, B). This element is almost complete, although the anteroventral part of the centrum is damaged. The amphicoelous centrum is rather long, with a length approaching $8 \mathrm{~mm}$, about double the height. The rim surrounding the notochordal concavity is swollen, increasing the concave curvature of the lateral and ventral edges. The pedicles are slightly shorter than the centrum, and bear very short transverse processes. Each transverse process arises from the middle part of the pedicle, and the long axis of the tuberculum facet is directed anteroventrally. The low neural spine is transversely slender and recurved posteriorly, tapering abruptly toward the apex to assume a nearly triangular shape in lateral view. The prezygapophyses are directed anterodorsally, extending slightly beyond the centrum anteriorly. The articular facet of each prezygapophysis is composed of a nearly vertical wall laterally and a nearly horizontal floor medially. Two sectors are separated medially by a ridge that is an anterior continuation of the neural spine. The postzygapophyses protrude posteriorly from the base of the neural spine and extend beyond the rim of the centrum. Their ventral edges are nearly horizontal. The distance 

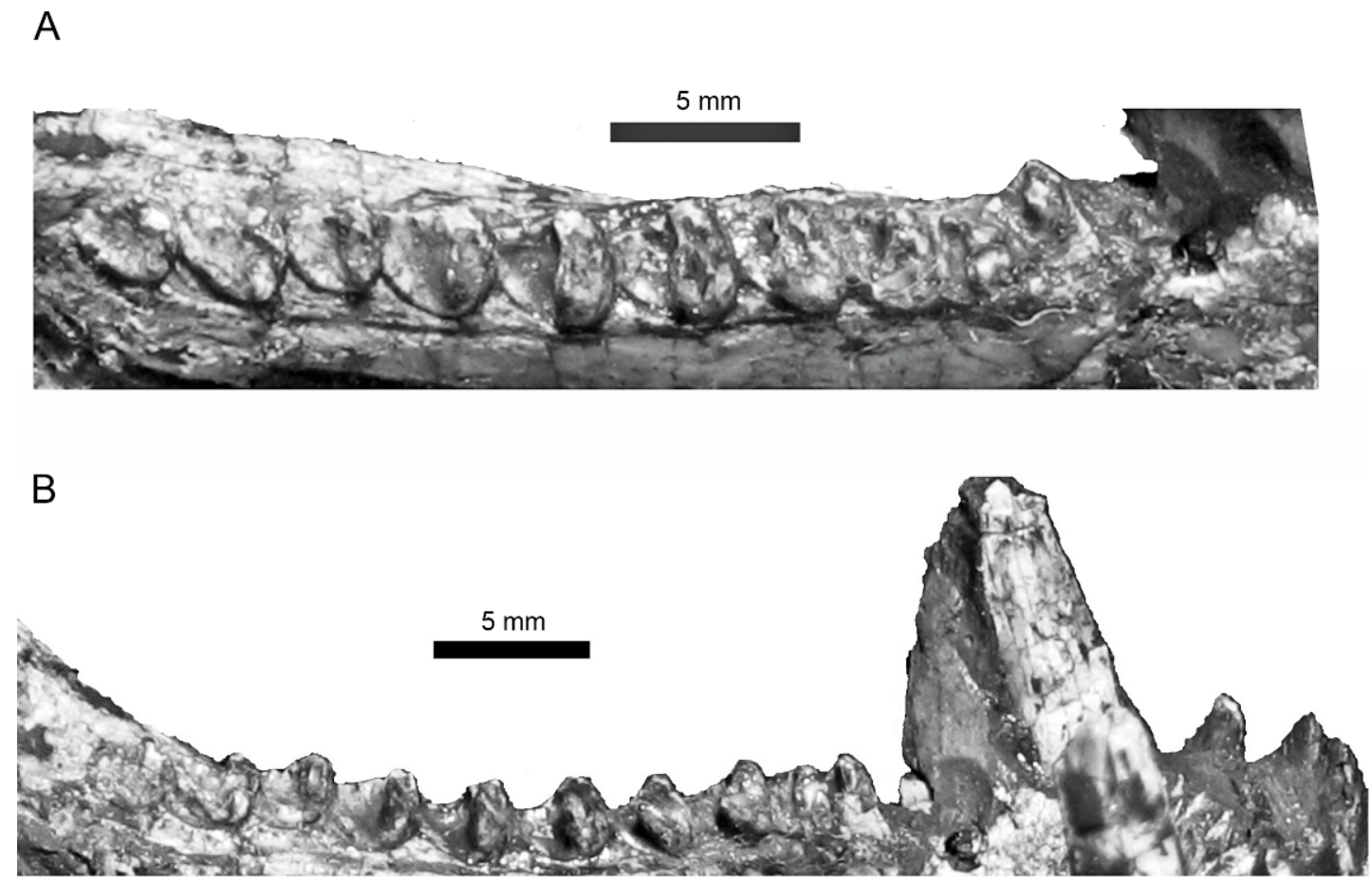

C

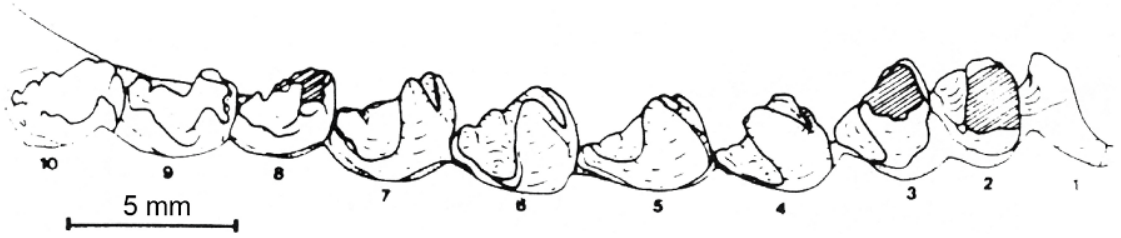

Fig. 8. Lower tooth series on left side (PVL 3894-1) in A, crown view; B and C, lingual view. C from figure 2 of Goñi and Goin (1988). Anterior is at right.

between the lateral margins is approximately $4 \mathrm{~mm}$ for the prezygapophyses, and $3.5 \mathrm{~mm}$ for the postzygapophyses. Anapophyses arise ventral to the postzygapophyses as elongate processes.

The continuous vertebral column of PVL 3894 includes 11 vertebrae and some ribs (5 on left side) (fig. 9C). Based on the similarity of the ribs with those of Pascualgnathus (MLP 65-VI-18-2), they probably come from the middle-posterior part of the dorsal region. The centra are approximately $1 \mathrm{~cm}$ long, with rounded ventral edges. The preserved ribs are joined to the transverse processes and bear triangular costal plates. The rib shaft extends beyond the costal plate in the anteriormost preserved rib, but not in the other ribs. Using the criterion that Jenkins (1971) applied to Thrinaxodon, this marks the boundary of the thoracic and lumbar regions, i.e., the anteriormost vertebra associated with rib preserved in the continuous series is the last thoracic vertebra. The anterior margins of the costal plates are slightly concave or nearly straight, and the anterior expansion of each plate is smaller than the posterior expansion. The anterior corner of each plate overlaps the posterior expansion of the next most anterior plate in ventral view. The lengths of the ribs decrease posteriorly.

THE SACRAL REgION: Three sacral vertebrae and associated ribs are preserved in specimen 

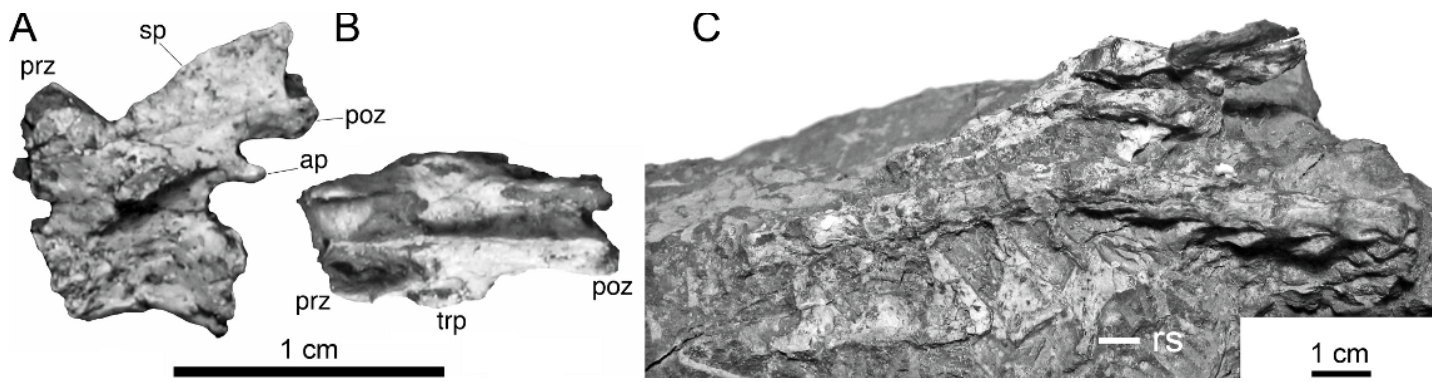

Fig. 9. PVL 3894, an anterior dorsal vertebra in A, lateral and B, dorsal views; $\mathbf{C}$, the dorsal region of the vertebral column in ventral view; anterior is at right. Abbreviations as in text.

PVL 4390, and are exposed in dorsal view (fig. 10). Although the posterolateral corner of one additional rib perhaps touches the cranial margin of the iliac blade, this rib is regarded as the last of the lumbar series, since that would correspond to the condition in Thrinaxodon

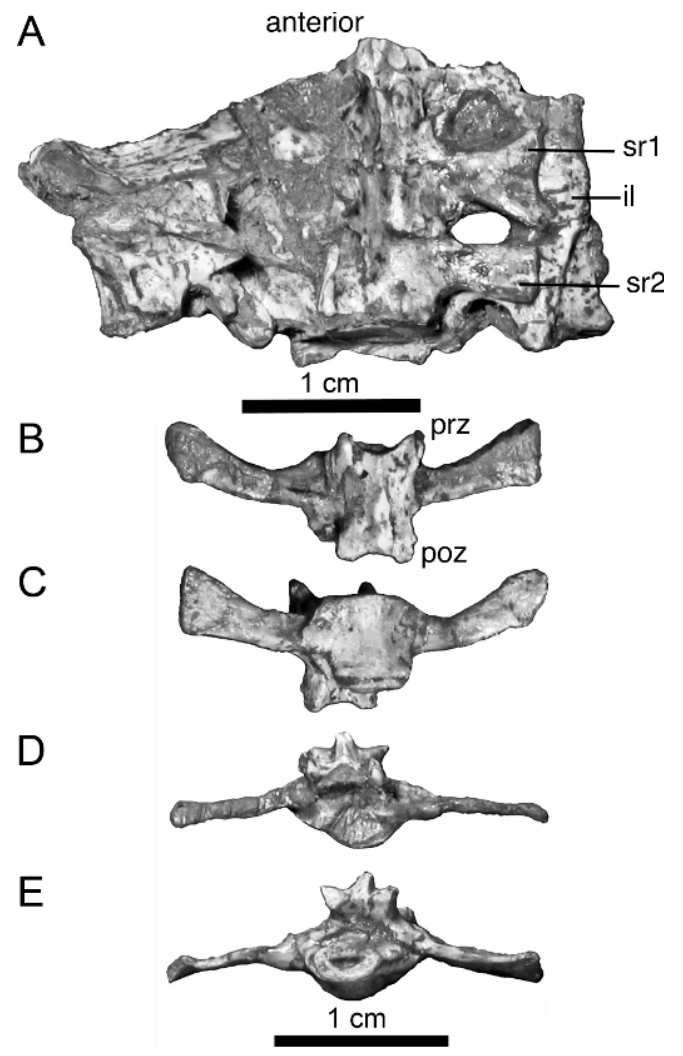

Fig. 10. PVL 4390. A, sacral region in dorsal view; third sacral vertebra and associated ribs in $\mathbf{B}$, dorsal, C, ventral, D anterior, and E, posterior views. Abbreviations as in text.
(Jenkins, 1971). Two genuine sacral ribs occupy most of the iliac blade, leaving enough space on the preserved surface of the blade for a maximum of one more posterior rib. Because this specimen is at most a subadult in which the posterior process of the ilium did not wholly ossify as in larger specimens (e.g., fig. 14C), the number of sacral vertebrae present in this species could in fact be greater than three, but a count greater than four is highly unlikely. An additional isolated vertebra present in PVL 4390 is identified as the third or fourth sacral. This bone is well preserved, apart from partial breakage of the neural spine.

Because each of the anterior two sacrals is covered by the postzygapophysis of the next most anterior vertebra, the exact lengths of these vertebrae are unknown. The isolated third sacral measures $5.5 \mathrm{~mm}$ in centrum length, and $7.5 \mathrm{~mm}$ from prezygapophysis to postzygapophysis. The sacral spines are relatively low and narrow anteroposteriorly (around $3 \mathrm{~mm}$ ).

The sacral ribs have confluent capitula and tubercula, short shafts, and expanded distal ends for articulation with the iliac blade. The first sacral rib measures around $4.5 \mathrm{~mm}$ in length but $5.5 \mathrm{~mm}$ in width of the distal end; the length and distal width of the second sacral are $4 \mathrm{~mm}$ and $3.5 \mathrm{~mm}$ respectively, and those of the third sacral are approximately $7 \mathrm{~mm}$ and $4 \mathrm{~mm}$ respectively. Accordingly, the transverse span across the distal ends of the paired ribs is largest in the third sacral. The distal end of the first sacral rib is emarginated. The anterolateral corner of this rib articulates with the ventral surface of the last lumbar rib, but the posterolateral corner 

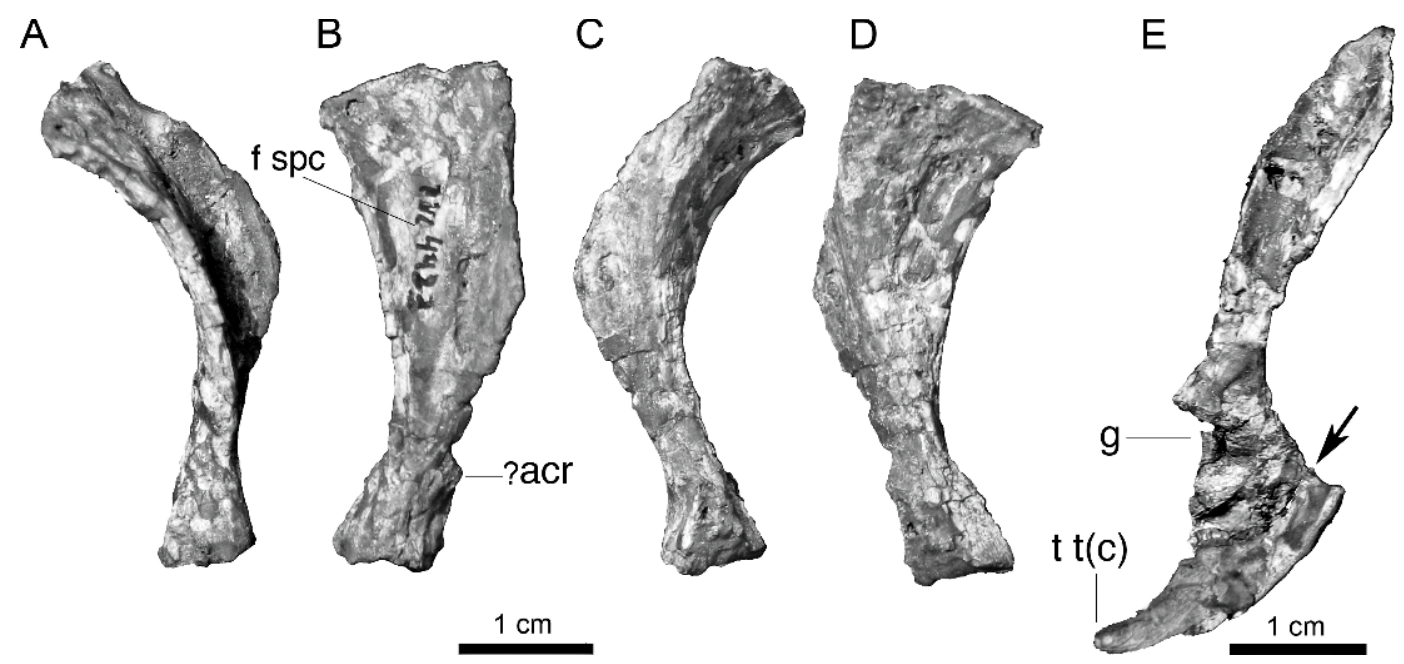

Fig. 11. PVL 4423, right scapula in A, posterior; B lateral; C, anterior; and D, medial views. PVL 4428, right scapulocoracoid in $\mathbf{E}$, lateral view. The arrow indicates the line of which two sides are glued in different directions. Abbreviations as in text.

does not contact the second sacral rib. The distal expansion of the first sacral rib is asymmetrical: the posterolateral corner is slightly more prominent than the anterolateral corner. The expansion of the second sacral rib is smaller and nearly symmetrical. The distal expansion of the third rib is more extensive anteriorly than posteriorly. The anterior two sacral ribs are directed almost laterally, whereas the third one is directed anterolaterally.

The number of sacral vertebrae varies in cynodonts: Jenkins $(1970,1971)$ counted six in Massetognathus, five in Thrinaxodon, and possibly six in Cynognathus, whereas Bonaparte (1966) suggested four in Pascualgnathus.

Pectoral GiRdLE: All components of the pectoral girdle are available in known material. The scapulae are known from the dorsal part of a left scapula (PVL 3890) and two incomplete right scapulae (PVL 4423 and 4428). A right coracoid and procoracoid are articulated with the scapula in PVL 4428. A nearly complete clavicle is preserved with an incomplete interclavicle in PVL 3894.

SCAPUlOCORACOID: The morphology of this element is rather uniform in Cynognathus, Diademodon, and Thrinaxodon (Jenkins, 1971), and the scapula of Andescynodon has this same basic shape. However, the scapular blade is more mediolaterally bowed as in Luangwa, especially in PVL 4423 (fig. 11AD). The flange of the cranial border is everted so that its edge is directed laterally. This flange increases in prominence ventrally, reaching a maximum around the middle point of the blade, then is gradually reduced in prominence and disappears above the acromion process. An acromion process is not observed in PVL 4428 (fig. 11E), while a short but distinct acromial protrusion is observed in PVL 4423 although this part of the scapula is not well preserved. The scapula is narrow and slightly elongated between the acromion and the glenoid.

The relationship of the coracoid and procoracoid with the scapula is unusual in the specimen PVL 4428: a sharply angled process is directed anteriorly rather than posteriorly. The lower part of the coracoid region has been glued to the upper part in reversed orientation, but this anomaly is corrected in figure 11E. The tuberosity for the origin of the coracoid head of the triceps lies well below and behind the glenoid.

Clavicle: A pair of isolated clavicles is known in PVL 3894, and both clavicles are intact apart from slight damage to their ends (fig. 12). The morphology is consistent with the general pattern in other cynodonts. The 


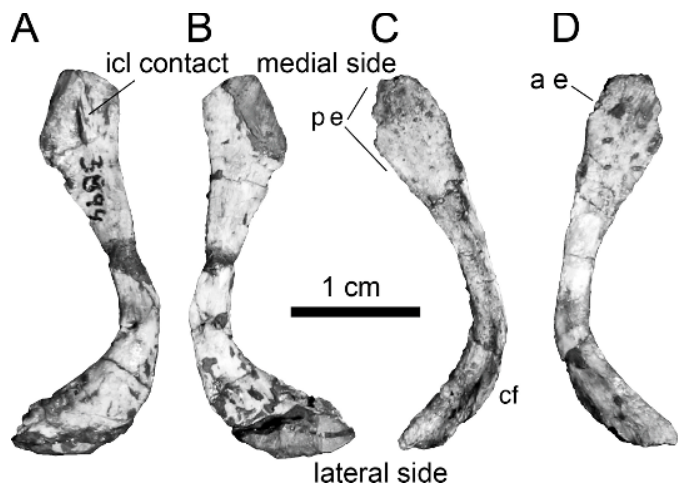

Fig. 12. PVL 3894, right clavicle in A, anterodorsal; and $\mathbf{B}$, posterior and slightly ventral views; left clavicle in $\mathbf{C}$, anterodorsal; and $\mathbf{D}$, posterior and slightly ventral views. Abbreviations as in text.

medial ramus of each clavicle is much longer than the lateral ramus and intersects with it at an angle of about $130^{\circ}$. The anterior edge of the medial end is not well preserved, but is clearly shorter than the posterior edge. The area of contact with interclavicle lies on the dorsal surface of the medial end, and this part of the clavicle bears visible striations. The clavicular flange retroverts slightly posteriorly from the lateral shaft, extending ventrad to the transitional place between the medial side and lateral side.

\section{FORELIMB}

Humerus: This bone is preserved in many specimens: PVL 3890 (fig. 13A-D), PVL 3894, PVL 4424 4427. Among these specimens, the length of the humerus ranges approximately from $30 \mathrm{~mm}$ to $43 \mathrm{~mm}$. The humerus resembles that of Thrinaxodon and most other traversodontids in its overall shape. The maximum width across the epicondyles is around half the humeral length.

Although the humerus is small, the extremities including the head and capitulum are well ossified. The ectepicondyle is a broad swelling on the distolateral corner of the humerus, and is thicker than the entepicondyle. Both an ectepicondylar foramen and an entepicondylar foramen are present, although the margin of the former is usually broken. The trochlea is well developed as in Cynognathus, Pascualgnathus, and Luangwa, especially in PVL 4426.

Ulna: One right ulna is present in PVL 3890 (fig. 13E), measuring $40 \mathrm{~mm}$ in height and about $12 \mathrm{~mm}$ in proximal width. The shape is the same as in Pascualgnathus. The articular surface for the humerus is only a very slightly concave facet, which is even less developed than in Massetognathus. The ulnar crest on the anteromedial margin is poorly preserved.

\section{Pelvic Girdle}

A single ilium is known in PVL 4390, and another in PVL 3890 (figs.10A, 14A). Two incomplete pelvic girdles are also known (fig. 14B, C). PVL 3894 includes an ilium, a nearly complete ischium, and an incomplete pubis exposed from the left side, whereas PVL 6226 comprises an ilium, an incomplete ischium, and a pubis exposed from the right side.

Ilium: The basic shape of this bone is similar to that seen in other traversodontids such as Luangwa (Kemp, 1980), Pascualgnathus (Bonaparte, 1966), and Massetognathus (Jenkins, 1970). The iliac blade is elongate anteroposteriorly, its length exceeding its height. The anterior process forms a convex flange, whose length anterior to the acetabulum is less than the acetabular height but greater than the anteroposterior diameter of the acetabulum. The height of the anterior process varies among specimens, PVL 3890 representing an extreme case in which the proportional height of the anterior process is greater than in other specimens and its anterior tip more obtuse. The ventral edge of the anterior process is relatively straight, and runs nearly parallel to the thin and sharp dorsal edge of the iliac plate. In lateral view, the anterior portion of the dorsal edge is convex in PVL 3890 and PVL 4390 but relatively straight in PVL 3894, whereas the posterior part is nearly horizontal (fig. 10A), slightly concave (fig. 14B, C) or distinctly concave (fig. 14A). The posterior process is low and short in PVL 4390 (fig. 10A), but much longer in other specimens. In PVL 3890 the length of the posterior process even exceeds that of the anterior process. The 

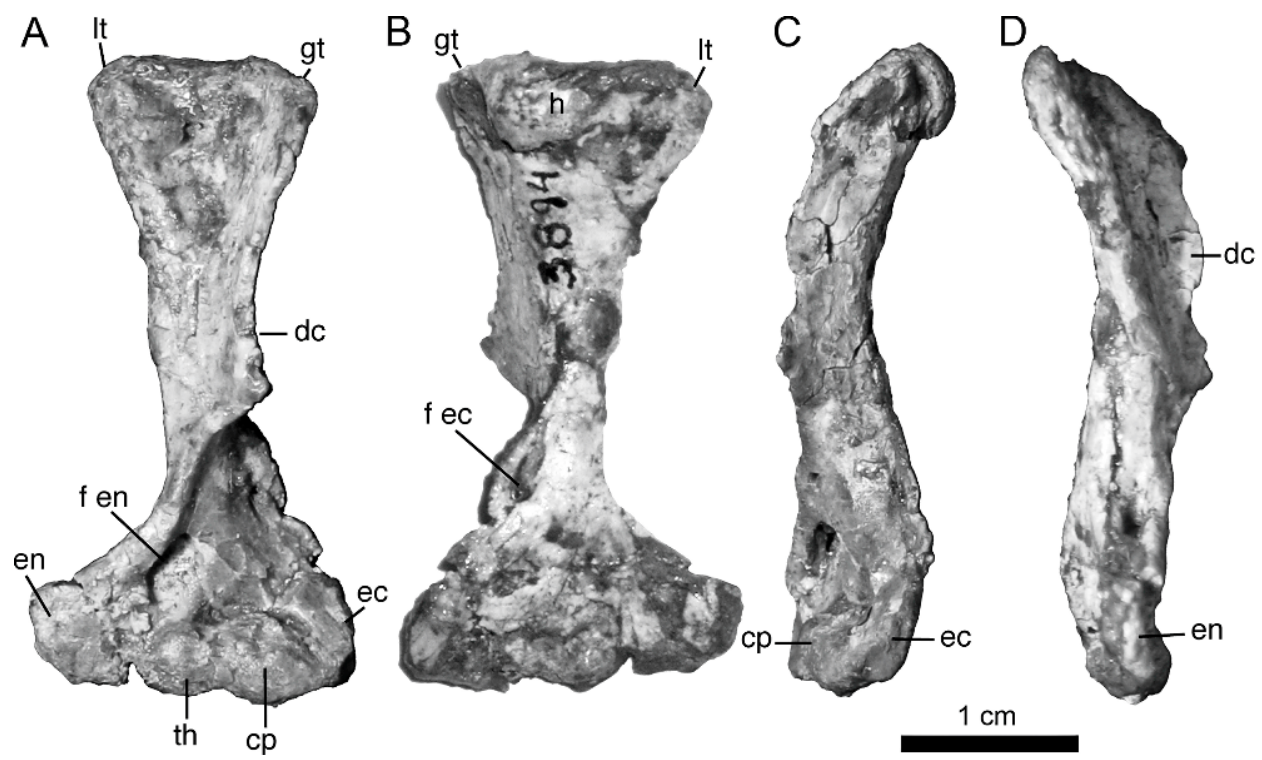

E

Fig. 13. PVL 3894, left humerus in A, dorsal; B, ventral; C, anterior; and D, posterior views; PVL 3890, E, right ulna in lateral view. Abbreviations as in text.

ventral edge of the posterior process is nearly straight, as in Massetognathus, and different from the concave shape seen in Luangwa and Pascualgnathus. The ventral edges of the anterior and posterior processes converge at an angle of $130^{\circ}$ in most specimens, similar to the condition in Pascualgnathus, but this angle is wider $\left(\sim 140^{\circ}\right)$ in PVL 3894. The lateral aspect of the blade is concave, but only slightly so in PVL 3890. The base of the ilium is a narrow neck with a breadth of less than $1 \mathrm{~cm}$ in PVL 3890 and 3894, a distance corresponding to less than one-quarter the length of the blade.

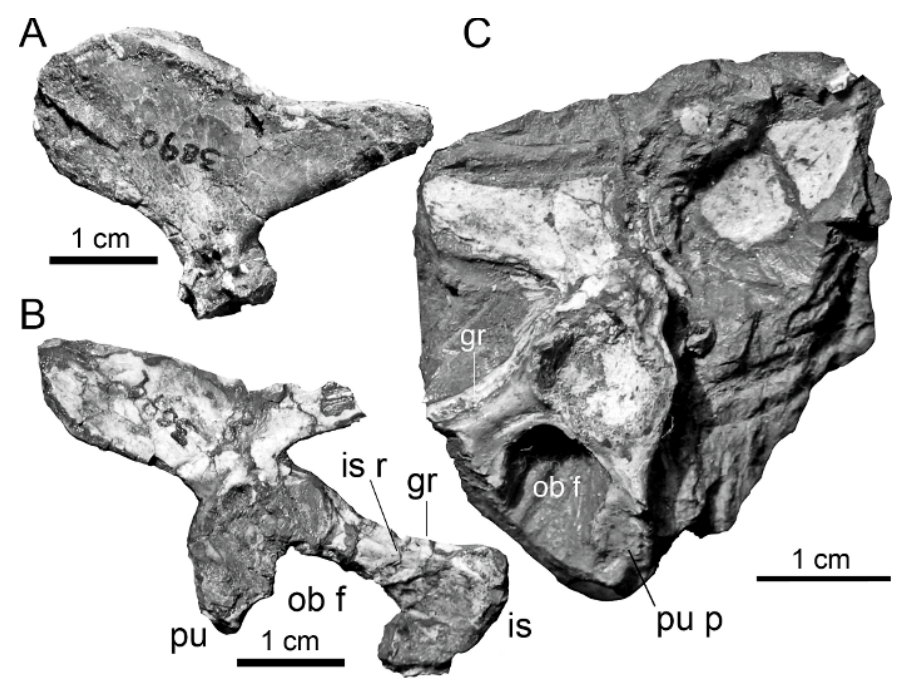

Fig. 14. Pelvis in lateral view. A, PVL 3890, left ilium; B, PVL 3894, left pelvis; C, PVL 6226, right pelvis. Abbreviations as in text. 
Some of the differences in the available four specimens mentioned above could be due to incompleteness or postmortem distortion. The posterior process obviously is incomplete in PVL 3894 and may also be missing its tip in PVL 6226 (fig. 14C), as the preserved shape of the end of the posterior process in this specimen is a bluntly rounded point that differs substantially from the sharp point seen in traversodontids such as Pascualgnathus (Bonaparte, 1966), Massetognathus (Jenkins, 1970), and Luangwa (Kemp, 1980). If the missing part is restored to reflect the morphology of these taxa, the length of the posterior process is close to that of the anterior process.

Differences in the curvature of the upper margin could also be explained in part by incomplete preservation. Furthermore, as Jenkins (1970) mentioned with respect to African cynodonts, a cartilaginous suprailiac blade may have been present, so that variations in the shape of the fossilized blade may at least partly reflect differences in ossification. This is particularly likely in the subadult specimen PVL 4390, in which the iliac blade appears complete, but the posterior process is nevertheless very short.

The shape of the ilium of PVL 3890 (fig. 10A) is strongly distinguished by the high anterior process, which is more similar to Cynognathus than other traversodontids. Because the morphology of this bone is so different from the condition in other available specimens, it is reasonable to ask whether the ilium of PVL 3890 actually pertains to a different species. However, the only known another cynodont species from the same formation is a trithelodontid, Cromptodon mamiferoides, and the ilium of trithelodontids is characterized by the complete lack of a posterior process. Accordingly, neither the ilium of PVL 3890 nor any of the other, more typical ilia described in this study can possibly be assigned to Cromptodon. Furthermore, both morphotypes are associated with definite skulls of Andescynodon. Accordingly, we tentatively accept both iliac morphotypes as pertaining to $A$. mendozensis, and attribute the difference between the morphotypes to intraspecific variation.

Pubis: The distal end of the pubis is not preserved (fig. 14B, C). The preserved part of the pubis has the same basic shape as in early cynodonts, and looks very similar to the pubis of Pascualgnathus. The constrained neck is distinct below the pubic head, while the pubic plate is less anteroposteriorly expanded. The anterior edge of the pubis is reflected laterally, achieving an anterolateral orientation. The proximal part of the pubic plate forms a concave lateral surface. The pubis extends ventrally and slightly medially from the acetabular region.

The exact orientation of the pelvic girdle is difficult to establish from the isolated bones. If the ventral edge of the posterior process of the iliac blade is assumed to be nearly horizontal, the pubis lies entirely anterior to the acetabulum and is directed slightly anteriorly.

In Luangwa, Kemp (1980) interpreted an unossified area between the pubis and ilium, on the anterior edge of the pelvis, as indicative of the presence of an epipubic element. This part of the pubis is completely ossified in the specimens described in the present study, so there is no evidence for an epipubic element in Andescynodon.

Ischium: The ischium is nearly complete in PVL 3894 (fig. 14B). This bone comprises a head, which contributes to the acetabulum, and a ventromedially and posteriorly directed plate. The ischial ridge is not well developed on the dorsal side of the plate, but a groove formed by the concavity of the dorsal side extends from the head and terminates on the ischial tuberosity (fig. 14B). The mediolateral width of the dorsal side of the plate decreases from the head toward the tuberosity. The anterior part of the ischium, which meets the posterior edge of the pubic plate, is only partly preserved. The part of the anterior edge that contributes to the obturator foramen is smooth and concave. The posterior edge is continuous with the ischial symphysis as a convex border.

The sutural relationships among the three pelvic bones are unclear in the acetabulum, where these bones form a unified hemispherical socket.

\section{HindLIMB}

FEMur: Only two left femora are known from PVL 3890 and PVL 3894. The femur of 


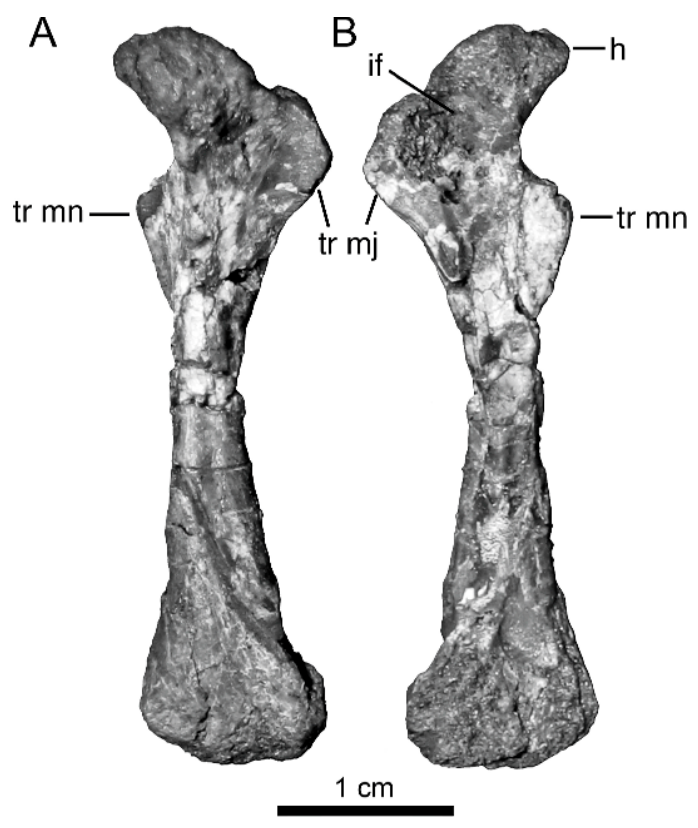

Fig. 15. PVL 3894, left femur in A, anterior; and $\mathbf{B}$, posterior views. Abbreviations as in text.

the latter specimen is better preserved, and is described below (fig. 15). The femur is $43 \mathrm{~mm}$ in height. The narrowest point on the slender shaft is less than $5 \mathrm{~mm}$ in diameter. The proximal end is expanded.

The femoral head is deflected medially and anterodorsally, and is offset conspicuously from the axis of the shaft. The trochanter major is separated from the head by a shallow groove. A round intertrochanteric fossa (adductor fossa of Kemp, 1980) lies between the head and the trochanter major on the ventral surface of the femur. The trochanter minor is a prominent, medially deflected flange that can be clearly seen even in dorsal view, as is also the case in PVL 3890. The distal end of the femur of PVL 3890 expands gradually, with a width of $11 \mathrm{~mm}$. The lateral and medial condyles are not preserved.

\section{DISCUSSION}

A number of cynodont skulls from the Cerro de las Cabras Formation have been referred to Rusconiodon because of their evident canine hypertrophy. The perforation of the skull roof by the paracanine fossae has been interpreted as a cranial feature that functioned to lodge the enlarged lower canine. Skulls referred to Andescynodon do not show the perforation of the skull roof by the paracanine fossa, but it is unclear whether this apparent difference from Rusconiodon should be attributed to interspecific or intraspecific variation. It is unlikely that the difference is an artifact of postmortem damage or distortion because an upper perforation of the paracanine fossa has been observed in many specimens, some well preserved.

Almost all specimens referred to Rusconiodon by Abdala (2000) have a basicranial skull length greater than $90 \mathrm{~mm}$, although PVL 3834 is an exception with a skull length of only $76 \mathrm{~mm}$. The snout is incomplete in PVL 3834 and the right lower canine appears to penetrate the skull roof via the paracanine fossa, whereas the dorsal surface of the left side of the snout looks complete. The condition of the right side could be the result of damage, so referral of this skull to Rusconiodon is dubious even in Abdala's (2000) terms. In known specimens, the proportional height of the canines generally increases with increased skull length (table 1), raising the possibility that specimens attributed to Andescynodon and Rusconiodon actually represent different growth stages of the same species. The seemingly greater length of the canines in specimens assigned to Rusconiodon, and the perforation in the roof of the paracanine fossa to accommodate the lower canine, would then simply result from maturity rather than from any taxonomic difference.

Because insufficient data on the lower canine are available, only data from seven individuals on skull length and upper canine height are analyzed here. They can be divided into an Andescynodon group and a Rusconiodon group. Using the equation of allometry $\ln y=a \ln x+b$, a regression was performed by the reduced major axis method, resulting in the line $\ln y=$ $1.93 \ln x-6.30$ (fig. 16). A large fraction of the growth of the canine can be explained as a function of skull length $(r=0.95)$, and the height of canine shows significant positive allometry relative to skull length $[\mathrm{p}(\mathrm{a}=1)=$ 0.009]. This allometry accounts for most of the variance in upper canine height across individuals. This suggests that the specimens do indeed 


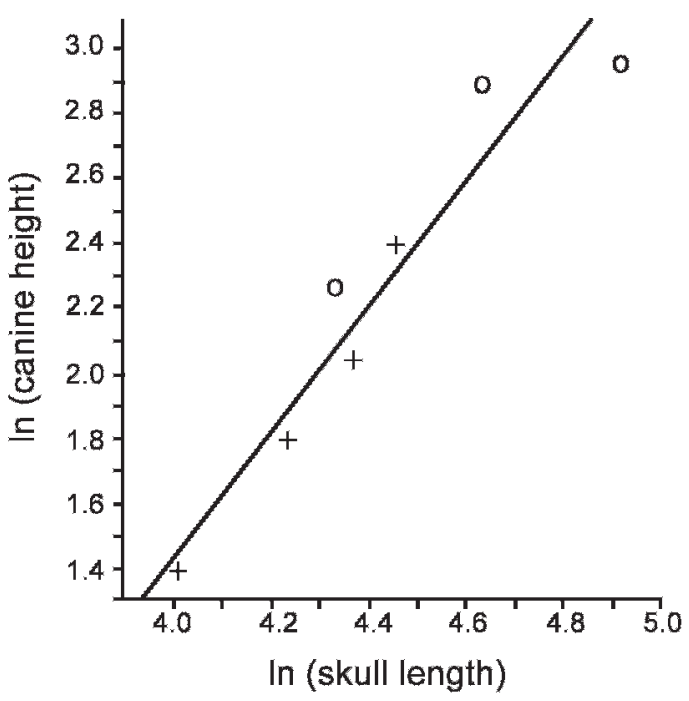

Fig. 16. Regression of upper canine length on skull length: In means "natural logarithm"; circles indicate specimens referred to Rusconiodon, and crosses indicate specimens referred to Andescynodon.

belong to a continuous growth series in which the proportional length of the upper canine tends to increase with the length of the skull. Furthermore, a similar variability in the paracanine fossae is observed in Pascualgnathus: the holotype of Pascualgnathus is similar to that of Rusconiodon with perforated fossae, but PVL 3466 has an Andescynodon-like skull, lacking perforation.

Because the two species are also very similar in other aspects of their morphology, we suggest that Rusconiodon mignonei is a junior synonym of Andescynodon mendozensis and should be discarded.

Andescynodon is very similar to Pascualgnathus. The upper postcanines of the two taxa are nearly identical in shape, while the lower postcanine morphology is unclear in Pascualgnathus. In both taxa the transverse ridge lies on the anterior margin of the tooth, not the posterior margin as in other traversodontids, although with wear the ridge assumes a nearly central position. The lower canines penetrate the paracanine fossae in adult specimens of both Andescynodon and Pascualgnathus. Andescynodon also has a small zygomatic process on the jugal, as in Pascualgnathus. However, the two genera can be easily differentiated by the number of upper incisors, since Pascualgnathus is more derived in possessing three, rather than four, incisors. Adults of Pascualgnathus also have more postcanine teeth and a longer postcanine tooth series for at least the upper jaw. Moreover, Andescynodon differs from Pascualgnathus in the shape of the skull, which is relatively flat, and in the temporal fenestra, which is shorter and relatively narrower. The ratio of occipital height to basicranial length is less than $35 \%$ for all individuals of Andescynodon, but is greater than $40 \%$ for Pascualgnathus. The ratios of temporal length and width to skull length in Andescynodon are less than the corresponding values in similar sized individuals of Pascualgnathus.

Most elements of the postcranial skeleton are known in Andescynodon. In traversodontids, the postcranial skeleton has been described in Traversodon stahleckeri (von Huene, 1935-42), Exaeretodon argentinus (Bonaparte, 1963), Pascualgnathus polanskii (Bonaparte, 1966), Massetognathus pascuali (Jenkins, 1970), and Luangwa drysdalli (Kemp, 1980). The postcranial skeleton of Andescynodon is nearly identical to that of Pascualgnathus polanskii, including the morphology of the ribs. Although the sacral ribs of Andescynodon look different from those depicted by Bonaparte (1966: fig. 7) for Pascualgnathus, the sacral ribs are incompletely preserved in the original Pascualgnathus specimen. Most postcranial features of Andescynodon, such as the shape of the costal plate, the pectoral girdle, and the humerus, as well as the angle between the ventral margins of the anterior and posterior processes of the ilium, are also similar to Diademodon (Jenkins, 1971), indicating that the postcranial morphology of Andescynodon may be essentially primitive. The postcranial skeletons of traversodontids in general will be discussed in more detail in another paper.

\section{ACKNOWLEDGMENTS}

The senior author thanks the Abdala family for their hospitality during his visit to Tucumán and Corwin Sullivan for editorial review. This paper is greatly improved by the suggestions from Fernando Abdala and another anonymous reviewer. This study is 
supported by the Theodore Roosevelt Memorial Fund, the National Foster Talent Fund of China (J0630965) and a grant from the Chinese Academy of Sciences (KZCX2YW-BR-07).

\section{REFERENCES}

Abdala, F. 2000. Catalogue of non-mammalian cynodonts in the vertebrate paleontology collection of the Instituto Miguel Lillo, Universidad Nacional de Tucumán, with comments on species. Ameghiniana 37: 463-476.

Abdala, F., J. Neveling, and J. Welman. 2006. A new trirachodontid cynodont from the lower levels of the Burgersdorp Formation (Lower Triassic) of the Beaufort Group, South Africa and the cladistic relationships of Gondwanan gomphodonts. Zoological Journal of the Linnean Society 147: 383-413.

Abdala, F., and A.M. Ribeiro. 2003. A new traversodontid cynodont from the Santa Maria formation (Ladinian-Carnian) of southern Brazil, with a phylogenetic analysis of Gondwanan traversodontids. Zoological Journal of the Linnean Society 139: 529-545.

Bonaparte, J.F. 1963. Descripción del esqueleto postcraneano de Exaeretodon (Cynodontia Traversodontidae). Acta Geologica Lilloana 4: 5-52.

Bonaparte, J.F. 1966. Una nueva 'fauna' triásica de Argentina (Therapsida: Cynodontia Dicynodontia). Consideraciones filogenéticas y paleobiogeográficas. Ameghiniana 4: 243-296.

Bonaparte, J.F. 1967 (published in 1969). Dos nuevas "faunas" de reptiles triásicos de Argentina. Gondwana Stratigraphy (IUGS symposium): 283-306.

Bonaparte, J.F. 1970. Annotated list of the South American Triassic tetrapods. In Proceedings and Papers: Second Gondwana Symposium, South Africa 1970: 665-682. Pretoria: CSIR.

Godefroit, P., and B. Battail. 1997. Late Triassic cynodonts from Saint Nicolas de Port (northeastern France). Geodiversitas 19: 567-631.
Goñi, R. 1986. Reemplazo de dientes postcaninos en Andescynodon mendozensis Bonaparte (Cynodontia, Traversodontidae). Actas del IV Congreso Argentino de Paleontología y Bioestratigrafía: 7-14.

Goñi, R., and F. Abdala. 1989. Consideraciones sobre la morfologia craneodentaria de Rusconiodon mignonei Bonaparte (Cynodontia, Traversodontidae): diagnosis, afinidades y variaciones ontogenéticas. Ameghiniana 25: 237-244.

Goñi, R., and F.J. Goin. 1987. El origen de los postcaninos gonfodontes de Andescynodon mendozensis Bonaparte (Cynodontia, Traversodontidae). Ameghiniana 24: 235-239.

Goñi, R., and F.J. Goin. 1988. Morfología dentaria y biomecanica masticatoria de los cinodontes (Reptilia, Therapsida) del Triásico Argentino. I, Andescynodon mendozensis Bonaparte (Traversodontidae). Ameghiniana 25: 139-148.

von Huene, F.F. 1935-42. Die fossilen Reptilien des südamerikanischen Gondwanalandes. Ergebnisse der Sauriergrabungen in Südbrasilien, 1928/1929. München: C. H. Beck.

Jenkins, F.A., Jr. 1970. The Chañares (Argentina) Triassic reptile fauna. VII, The postcranial skeleton of the traversodontid Massetognathus pascuali (Therapsida, Cynodontia). Breviora 352: 1-28.

Jenkins, F.A., Jr. 1971. The postcranial skeleton of African cynodonts; problems in the early evolution of the mammalian postcranial skeleton. Peabody Museum of Natural History Bulletin 36: 1-216.

Kemp, T.S. 1980. Aspects of the structure and functional anatomy of the Middle Triassic cynodont Luangwa. Journal of Zoology 191: 193-239.

Quiroga, J.C. 1980. Further studies on cynodont endocasts (Reptilia - Therapsida). Zeitschrift fuer Mikroskopisch-Anatomische Forschung (Leipzig) 94: 580-592.

Zavattieri, A.M., and A.B. Arcucci. 2003. Edad y posición estratigráfica de los tetrápodos de la localidad Cerro Bayo de Potrerillos (Triásico), Mendoza, Argentina. Ameghiniana 40: 75R. 
Complete lists of all issues of the Novitates and the Bulletin are available at World Wide Web site http://library.amnh.org/pubs. Inquire about ordering printed copies via e-mail from scipubs@amnh.org or via standard mail from: American Museum of Natural History, Library-Scientific Publications, Central Park West at 79th St., New York, NY 10024. TEL: (212) 769-5545. FAX: (212) 769-5009. 